\title{
A macro-fracture investigation of the backed stone tools from Dzombo Shelter, eastern Botswana
}

Tim Forssman

Anthropology and Archaeology Department, University of Pretoria, South Africa

Cnr. Lynnwood and University Roads, Humanities Building 8-5, Anthropology and Archaeology Department, University of Pretoria, Pretoria, 0023, South Africa

Contact: +27784224828

Email: tim.forssman@gmail.com

\begin{abstract}
Foragers occupying Dzombo Shelter, eastern Botswana, and producing a Later Stone Age technology came into contact with incoming Iron Age food-producers at approximately AD 350. From the onset of their interactions the Later Stone Age record began to change. One such change was in stone tool preference; over much of southern Africa scraper frequencies increased whereas backed tools declined. However, between c. AD 900 and 1200 at Dzombo, backed tools inexplicably dominate the formal tool assemblage. This paper seeks to understand the role of backed tools at Dzombo from before the arrival of farmers until the establishment of the Mapungubwe state, c. AD 1220, in order to explain shifts in use and preference patterns. By performing a macro-fracture analysis it was possible to demonstrate an increased occurrence of fractures consistent with impact-related damage between approximately AD 350 and 1200, and it is suggested here that during this time hunting activities were intensified. The factors possibly driving this intensification are discussed and could relate to forager-farmer interactions or a shift in the site's function. As is shown, the former is more likely. The macro-analysis of backed tools provides greater clarity when viewing Dzombo's archaeological sequence and to some extent confirms earlier suggestions that in order to augment growing mercantile opportunities spurred on by the arrival of farmers, forager hunting activities increased.
\end{abstract}

Keywords: Macro-fractures; diagnostic impact fractures; Later Stone Age; hunting; forager-farmer interaction; southern Africa

\section{Introduction}

Within the last 2000 years, changes ranging from the introduction of ceramics, glass beads and domesticates to shifts in formal stone tool preferences have been recorded in southern Africa's Later Stone Age sequence. One notable change was an increase in the frequency of scrapers and corresponding decline of backed tools in most forager assemblages (e.g. Walker 1994; Wadley 1996; Sadr 2002). This trend continued and intensified over the last two millennia until the production of stone tools ceased in more recent centuries (see Lombard et al. 2012). It is thought that this shift was prompted by the arrival of farming communities within the last 1800 years (see Huffman 2007: xi for dates) and their subsequent interactions with local foragers. It is thought that, amongst other goods (see Sadr 1997), foragers used animal hides as trade goods and scraping tools were used in their preparation (Deacon \& Deacon 1980). To acquire hides, foragers likely used metal arrow inserts 
acquired from farmers. This effectively removed the need for backed tools(e.g. Parkington 1980; J. Deacon 1984a; Wadley 1987; H. Deacon 1989, 1995; Lombard \& Pargeter 2008; Lombard \& Parsons 2008; Mohapi 2008; Villa \& Soriano 2010), shown through experimentation and macro- and microanalyses to have been used as hunting tools (e.g. Lombard \& Parsons 2008; Shea 2009; Villa et al. 2010; Pargeter 2011). With few exceptions, this pattern has been recorded across southern Africa.

This is no different on the Greater Mapungubwe Landscape (Figure 1) all but one of the excavated Later Stone Age sites. The only exception is Dzombo Shelter. From the lower levels dating to $c$. 200 $B C$, scraping and backed tools vary in frequency with scraping tools becoming progressively more frequent and dominating after $A D$ 350. Around AD 900, and corresponding with the arrival of Zhizo ceramic-producing farmers, the frequency of scrapers suddenly drops with a steep increase recorded in the number of backed tools (Figure 2). This trend continues until about c. AD 1200 at which point scrapers once again dominate (see Forssman 2014a \& 2014b). This second shift occurs immediately prior to the establishment of southern Africa's first state level society, Mapungubwe, approximately AD 1300 (see Huffman 2000 for dates). While at Dzombo radiocarbon dates suggest a possible mid-second millennium AD occupation (Forssman 2014b), at all other sites Later Stone Age material remains disappears (van Doornum 2005; Forssman 2014a).

The aim of this paper is to provide additional insights into the function of and changing preference for backed tools during Dzombo's occupation. It is hypothesised that when farmers arrived in the area, c. AD 350, hunting activities intensified possibly due to trade in animal products, such as meat and hides (see Sadr 1997), or because foragers were used as specialist hunters. During this time, many excavated farmer homesteads have revealed a faunal assemblage dominated by wild game (e.g. Voigt 1980, 1981; Voigt \& Plug 1981; Plug 1988; Antonites 2014: 180-182). It has also been suggested that at first farmers at commoner sites did not have access to metal (Calabrese 2000). Thus, foragers may have been relied upon to obtain wild game and since metal was not readily available they produced large amounts of backed tools as weapon composites. To test whether hunting did indeed increase during this time, the backed tool assemblage was analysed for impactrelated macro-fractures using Fischer et al. (1984), Lombard (2005) and Pargeter's (2011) methods. If there are higher proportions of backed tools containing fractures associated with impact damage in the 'contact' levels, then it would provide one line of evidence to suggest that hunting activities were intensified during this phase. 


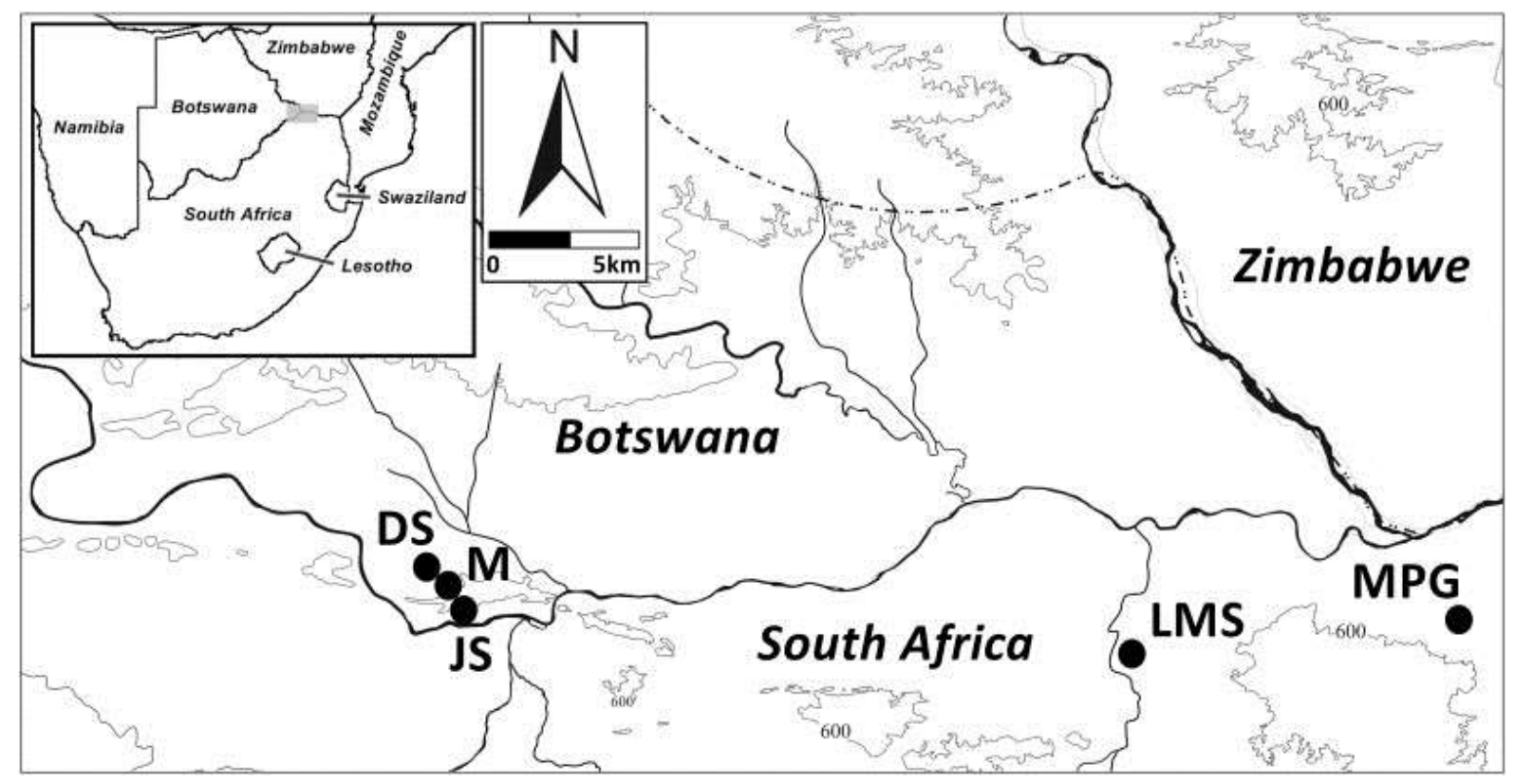

Figure 1: The Greater Mapungubwe Landscape with other important sites: DS, Dzombo Shelter; JS, João Shelter; LMS, Little Muck Shelter; M, Mmamagwa; and MPG, Mapungubwe.

\section{Scraper and backed tool density}

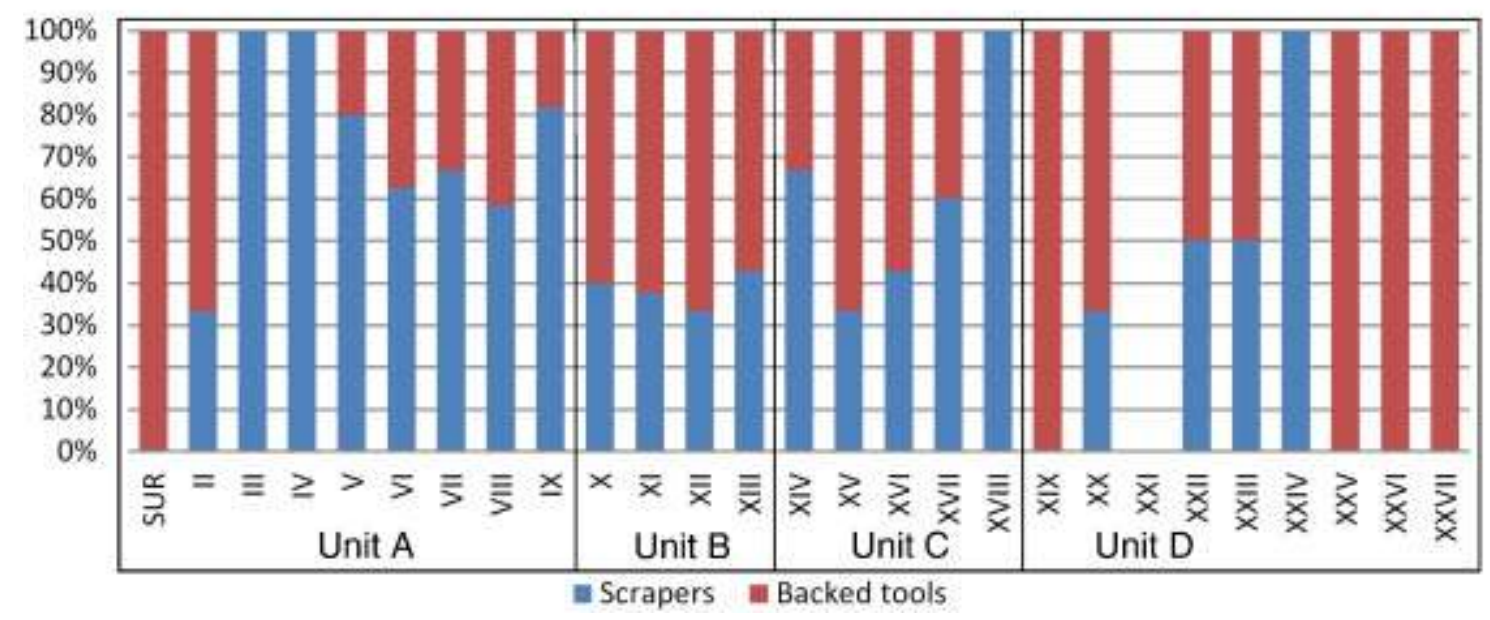

Figure 2: Distribution of scrapers and backed tools per bucket (density calculated by dividing stone tool numbers by 13 I buckets removed per spit). Units $A$ to $D$, where Unit $D$ dates to before $c$. $A D$ 350 (c. 200 BC radiocarbon date from Spit XIX; see below), are discussed below.

\section{Methods}

Backed stone tools are defined as having a single sharp working edge opposite a steeply blunted edge done so deliberately for hafting purposes. At Dzombo this includes complete and broken versions of 1 ) backed bladelets, in which the length is double the measurement of the width; 2 ) segments, which are similar in appearance but crescent in shape; and 3) segmented backed bladelets, which appear segment-like but are intentionally not arched the entire way through and end abruptly, thus differentiated from either backed bladelets or segments (see J. Deacon 1984b for typology). All of Dzombo's backed tools were examined for macro-fractures but only those located 
at the proximal or distal ends where impact would occur were considered. Breaks exhibiting evidence of flaking, such as negative bulbs of percussion, were also excluded. In addition, the formation of macro-fractures is independent of raw material type (Fischer et al. 1984; Lombard et al. 2004 but see Pargeter 2013 and below), artefact morphology (Fischer et al. 1984) and size (Odell \& Cowan 1986; all artefacts were less than $30 \mathrm{~mm}$ and so size was not considered here). Regardless, all morphological attributes were recorded using a Nikon macro-magnifying glass. Fisher's exact test was used ( $p[F]$ values; $P \leq 0.05$; for details see Upton 1992; see section 3.1) in order to test whether a significant probability of fractures forming on specific tool forms or on certain material types exists. Furthermore, odds values (OR), a comparative test showing the odds of a variable occurring (Pargeter 2013: 7), was used to test whether there was significant change in the presence of backed tools and occurrence of fractures forming between the chronological units (for archaeological examples see Bird 2007; Tallavaara et al. 2010; Graves 2011). The formula used is $O R=$ $(U 1 a \times U 2 b) /(U 2 a \times U 1 b)$ where $\mathrm{U} 1$ and $\mathrm{U} 2$ are the different units, $a$ are backed tools containing impact fractures and $b$ are those without. If the OR value is higher than 1 , then there is a greater odd that the first group would acquire fractures (see section 3.2).

Not all macro-fracture types indicate hunting. However, it is possible to separate fracture types typically associated with impact, stabbing or thrusting (Pargeter 2011: 5) based on fracture initiation and termination characteristics (Lombard 2005). These fractures are known as diagnostic impact fractures but Pargeter (2013) suggests the term impact fracture is more appropriated and it is preferred here. In the Fischer et al. (1984) experiments, four main breakage types that are considered impact fractures were identified, three of which were recorded in this study. They are:

Spin-off fractures that are either unifacial or bifacial and are secondary fracture types forming off another bending fracture, such as step terminating (discussed below) or snap fractures (Pargeter 2011: 7), and exceed $1 \mathrm{~mm}$ in length (Fischer et al. 1984; Dockall 1997). However, Lombard (2005) warns that unifacial spin-off fractures $<6 \mathrm{~mm}$ could be the result of natural breakage and she excludes them from her study. It must be noted that studies which tend to avoid using spin-off fractures $<6 \mathrm{~mm}$ as an impact fracture have been on Middle Stone Age (MSA) assemblages (e.g. Lombard 2005, 2007; Lombard \& Pargeter 2008). If the same principles are applied to Later Stone Age microlithic artefacts, which sometimes contain formal tools little over $10 \mathrm{~mm}$, a large number of spin-off fractures would be excluded. In addition, Pargeter (2011) did not record the formation of spin-off fractures in any of his trampling experiments. Therefore, those $>1 \mathrm{~mm}$ are included here as impact fractures but they are nevertheless split into either $<$ or $>6 \mathrm{~mm}$.

Step terminating bending fractures (step terminating fractures) are longitudinal fractures terminating in an abrupt 90 step (Dockall 1997: 325; Pargeter 2011: 9). While these can form from trampling or knapping, when found without percussion bulbs and associated with medial or proximal ends of tools, the fracture either relates to hunting or hafting (Pargeter 2011: 7).

Impact burination bending fractures (impact burinations) form from a bending fracture that terminates in a $90^{\circ}$ step along a lateral edge along the face of a tool (Pargeter 2011: 9).

Impact notches (notches) are a potential fifth impact fracture. These are smooth semi-circular removals on the sharp edge of a tool and which contain no retouch (Lombard \& Pargeter 2008). Notches can possibly form when weapon tips are transversely hafted (Yaroshevich et al. 2010), but 
also form from cutting or slicing activities (Lombard \& Pargeter 2008). As such, they are not reliable stand-alone indicators of impact (Pargeter 2011: 105, 144-5).

While it is generally accepted that these fractures indicate some form of impact, caution is advised. Pargeter (2011), in his trampling experiments, recorded the formation of step terminating fractures and impact burinations indicating that animal trampling can cause fractures consistent with impact. It is thus important to determine the affect post-depositional processes have had on an assemblage (Pargeter \& Bradfield 2012). Doing so is possible. In his experiment Pargeter (2011) recorded very low frequencies of impact fractures (also see Lombard \& Pargeter 2008; Bradfield \& Lombard 2011) and Fisher et al. (1984) show that in an assemblage used for hunting, at least $40 \%$ of the tools should possess impact fractures. Therefore, the proportion of tools with impact fractures is significant. However, it is acknowledged that confirmation of macro-fracture analyses results should be sought through additional use-trace studies on, for example, residual remains and abrasion (e.g. Schweitzer \& Wilson 1982; Binneman 1983, 1997; Binneman \& Mitchell 1997; Dockall 1997; Lombard 2004, 2011Boëda et al. 2008). Macro-fractures, regardless, are a useful tool for establishing the potential function of stone artefacts, revealing additional insights into a site's function.

\section{Dzombo Shelter and its backed assemblage}

Presented here are the results from Trench 1 (Figure 3), located inside the rockshelter and excavated in spits of $30 \mathrm{~mm}$ to a depth of $81 \mathrm{~cm}$. A tightly controlled stratigraphic sequence was revealed, primarily composted of a large grey ash deposit (Figure 4). For this reason, spits are used when describing artefact provenance. Four radiocarbon dates were submitted to the Oxford Radiocarbon Accelerator Unit and one to Beta Analytic and coupled with chronological indicators, such as diagnostic ceramics and beads, were used to establish the site's sequence. The dating of the upper levels is uncertain since each of the three radiocarbon dates (from Spit IV, VII and VIII) indicate an age of within the last 400 years (all dates calibrated using SHCal04) whereas the ceramic and glass bead assemblages appear to belong between AD 1000 and 1300. However, dates of AD 1029 to 1162 (Spit XI) and 207 to $42 \mathrm{BC}$ (Spit XIX) correspond closely with other chronological indicators in those levels (see Forssman 2014a, 2014b). It therefore seems that Dzombo was occupied from before 2000 years ago until possibly within the second half of the second millennium AD, although it cannot be said whether it was occupied continuously.

In total, 10112 stone tools were recovered from Dzombo, of which 56 are backed (0.55\%; Table 1$)$. Segments comprise the majority of these $(n=28$; broken $=5)$, followed by segmented backed bladelets $(n=18$; broken $=1)$ and lastly backed bladelets $(n=10$; broken $=3)$. Most of the backed tools occur between Spits V and XVI $(n=45 ; 80.4 \%)$, corresponding with the depths at which most of the archaeological assemblage was recovered including the backed tool-dominated levels (Spits $X$ and XIII). It is these artefacts that are of interest in this study and presented below is the macrofracture analysis performed on them. This is followed by a summary of farmer- and trade-related artefacts found at the site, which includes ceramics, beads, metal items and bone tools, and then the faunal assemblage. When combined, these finds assist in understanding the shift in stone tool preferences. 


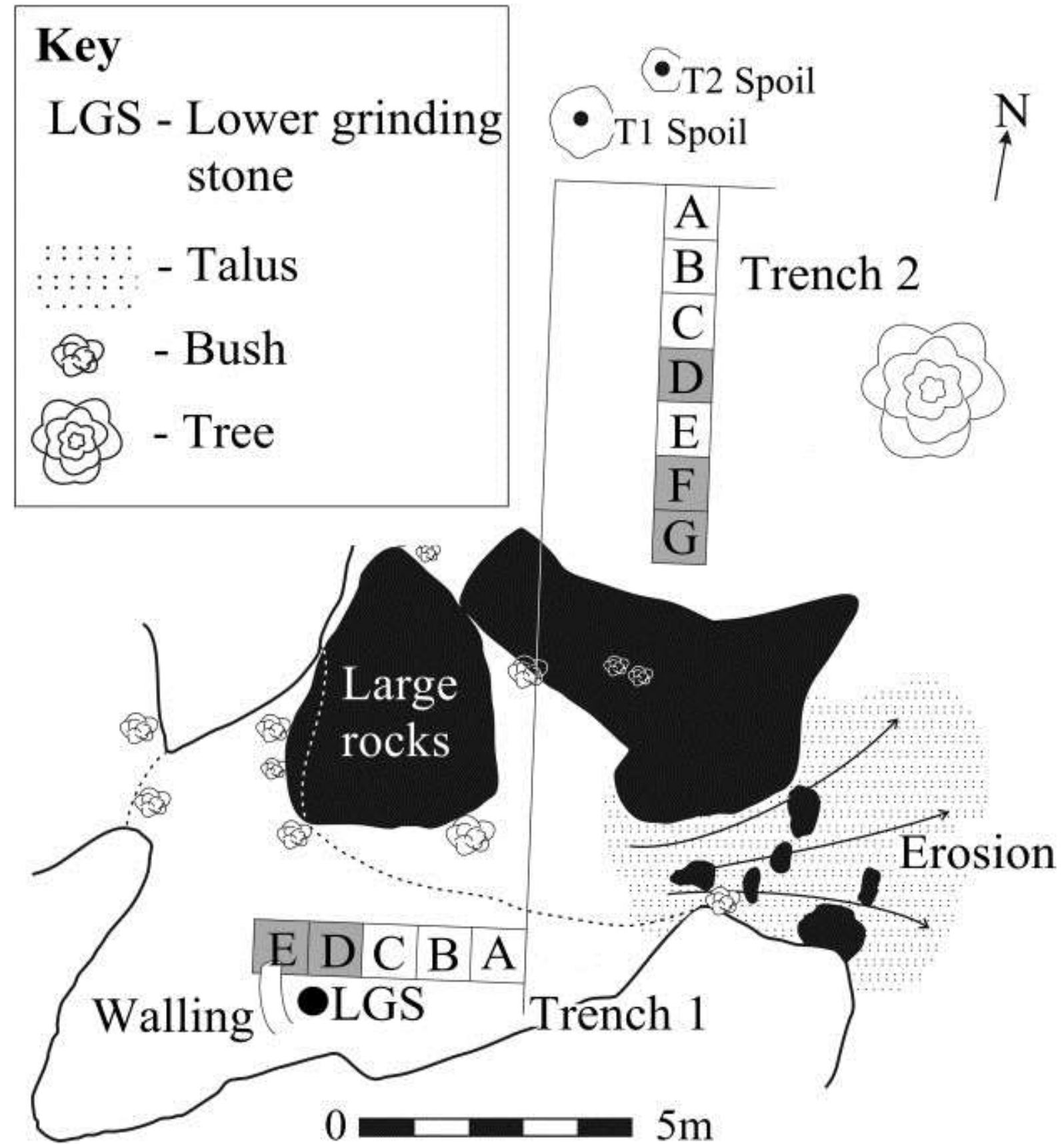

Figure. 3: A plan view of Dzombo Shelter showing Trench 1 (inside the rockshelter) and Trench 2 (in the open living area). 
Table 1: The distribution of backed tools and their raw material: CCS, crypto-crystalline silicates; BB, backed bladelet; SBB, segmented backed bladelet; SEG, segment; and BR, broken.

\begin{tabular}{|c|c|c|c|c|c|c|c|c|c|c|c|c|c|}
\hline & \multicolumn{5}{|c|}{ CCS } & \multirow{2}{*}{$\begin{array}{l}39 \\
\underline{u} \\
\text { W } \\
\frac{c}{0}\end{array}$} & \multicolumn{2}{|c|}{ Agate } & \multirow{2}{*}{$\begin{array}{l}10 \\
\text { 岃 }\end{array}$} & \multicolumn{2}{|c|}{ Quartz } & \multirow{2}{*}{$\begin{array}{c}7 \\
\text { 岕 } \\
\text { 品 }\end{array}$} & \multirow[b]{2}{*}{$\begin{array}{l}\frac{n}{\pi} \\
\stackrel{0}{\circ}\end{array}$} \\
\hline Spit & $\ddot{\varphi}$ & $\begin{array}{l}\infty \\
0 \\
0 \\
0\end{array}$ & $\begin{array}{l}\tilde{0} \\
\tilde{\sim}\end{array}$ & $\begin{array}{l}\boldsymbol{D} \\
\tilde{w} \\
\tilde{c} \\
\tilde{\omega}\end{array}$ & 岃 & & $\ddot{\infty}$ & $\begin{array}{l}\tilde{0} \\
\tilde{n}\end{array}$ & & $\begin{array}{l}\tilde{p} \\
\tilde{\tilde{n}}\end{array}$ & 岃 & & \\
\hline SUR & & & & & 1 & & & & & & & & 1 \\
\hline II & 1 & & & & & & & & & & & & 1 \\
\hline III & & & & & & & & & & & & & 0 \\
\hline IV & & & & & & & & & & & & & 0 \\
\hline $\mathrm{V}$ & & & & & & & & & & & 1 & & 1 \\
\hline VI & & & & & 2 & & & & 1 & & & & 3 \\
\hline VII & & 1 & & & 2 & & & 1 & & 1 & & & 5 \\
\hline VIII & 2 & & & & 2 & & & 1 & & & & & 5 \\
\hline IX & & & & & 1 & & & & & & & & 1 \\
\hline$x$ & & & 1 & & & & & & 1 & & & & 2 \\
\hline$X I$ & & & & & 3 & & 1 & 1 & & & & & 5 \\
\hline XII & & 1 & 3 & & 1 & 1 & & & & 1 & 1 & & 8 \\
\hline XIII & & & 1 & & & & & 1 & & & & & 2 \\
\hline XIV & 1 & & & & 1 & & & & & & & 1 & 3 \\
\hline$x V$ & 1 & & 2 & & 1 & & & 1 & & & & & 5 \\
\hline $\mathrm{XVI}$ & & & 1 & & 2 & & 1 & & & & & 1 & 5 \\
\hline $\mathrm{XVII}$ & & & & & & & & & & & & & 0 \\
\hline XVIII & & & & & 1 & & & & & & & 1 & 2 \\
\hline XIX & & & & & & 1 & & & & & & & 1 \\
\hline$x X$ & & & & & & & & & & & & & 0 \\
\hline$X X I$ & & & & & & & & & & & & & 0 \\
\hline XXII & & & & & & & & & & & & & 0 \\
\hline XXIII & & & & 1 & 2 & & & 1 & & & & & 4 \\
\hline XXIV & & & & & & & & & & & & & 0 \\
\hline$X X V$ & & & 1 & & & & & & & & & & 1 \\
\hline XXVI & & 1 & & & & & & & & & & & 1 \\
\hline XXVII & & & & & & & & & & & & & 0 \\
\hline
\end{tabular}

\begin{tabular}{llllllllllllll} 
Totals & 5 & 3 & 9 & 1 & 19 & 2 & 2 & 6 & 2 & 2 & 2 & 3 & 56 \\
\hline
\end{tabular}




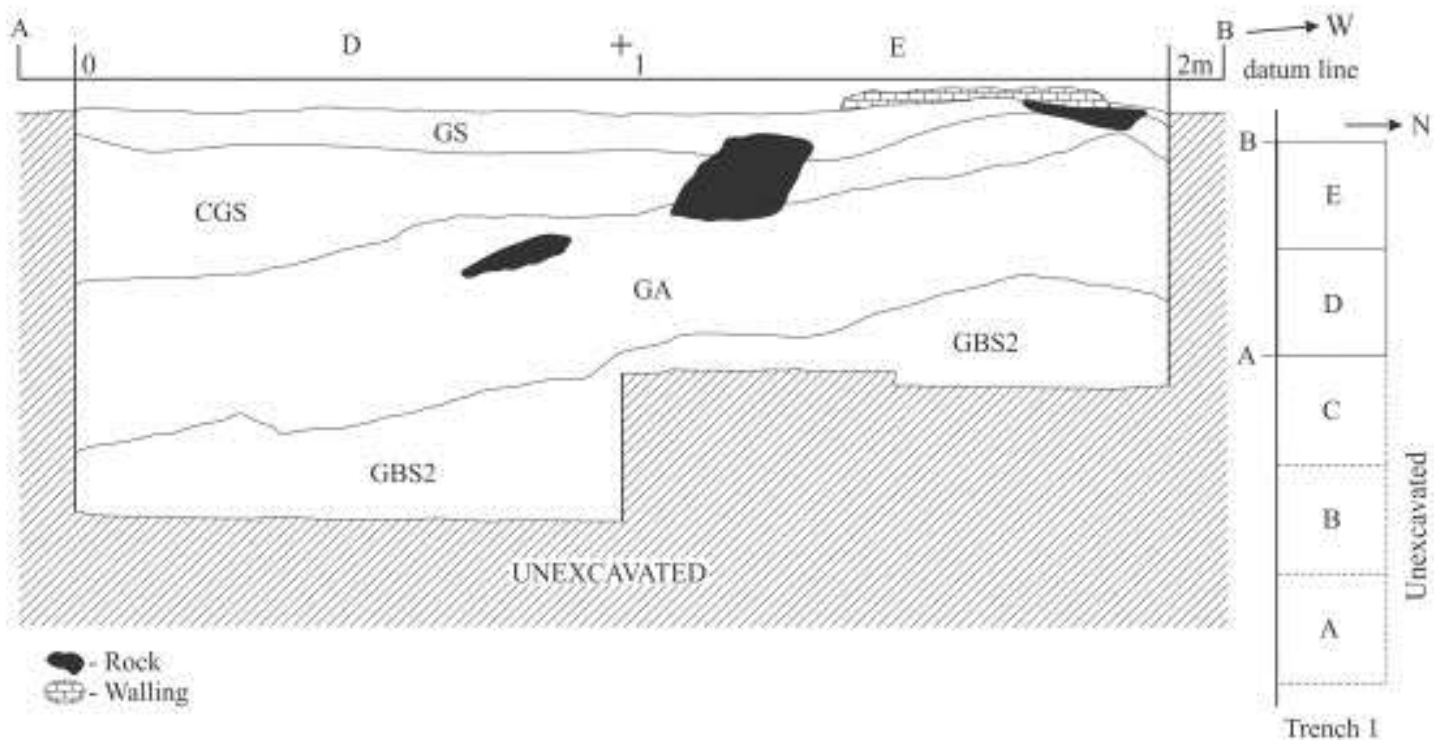

Figure 4: A section of Trench 1 showing the major stratigraphic units: GS, grey soil; CGS, compact grey soil; GA, grey ash and GBS2, grey-brown soil 2. (from Forssman, 2014b: 184)

\subsection{Macro-fracture analysis}

Of the 56 backed tools, 46 contained macro-fractures but only 38 were consistent with impactrelated damage (55.1\%; see Figure 5 for examples). If unifacial spin-off fractures $<6 \mathrm{~mm}$ are excluded this figure reduces to 30 tools containing impact fractures (43.5\%). However, the presence of impact fractures varied between the different back tool types (Table 2). In both the segment and segmented backed bladelet categories 16 impact fractures were identified while only six were recorded in the backed bladelet category (figures include complete and incomplete tool variants). When the number of fractures is offset by the number of tools it becomes clear that there are numerically more fractures per segmented backed bladelet $(n=0.89 /$ tool) than both backed bladelets $(n=0.6 /$ tool) and segments $(n=0.57 /$ tool). Though, when all fracture types are included, backed bladelets possess the most per tool $(n=1.8)$, followed by segmented backed bladelets $(n=$ 1.3 ) and segments $(n=1)$. While this could indicate that backed bladelets are more likely to acquire fractures whether during use or after deposition, Fisher's exact test reveals that no single tool type has a higher probability of forming an impact fracture than any other. If true, this is consistent with Fischer et al.'s (1984) conclusion that the formation of impact fractures is independent of tool morphology. It may be worthwhile to test this experimentally with a larger sample size. 
Table 2: Macro-fractures present on the various tool forms: BB, backed bladelet; SBB, segmented backed bladelet; SEG, segment; and BR, broken.

\begin{tabular}{|c|c|c|c|c|c|c|c|c|c|c|c|c|c|c|}
\hline & \multicolumn{2}{|c|}{ BB } & \multicolumn{2}{|c|}{ BR BB } & \multicolumn{2}{|c|}{ SBB } & \multicolumn{2}{|c|}{ BR SBB } & \multicolumn{2}{|c|}{ SEG } & \multicolumn{2}{|c|}{ BR SEG } & \multicolumn{2}{|c|}{ Totals } \\
\hline & No. & $\%$ & No. & $\%$ & No. & $\%$ & No. & $\%$ & No. & $\%$ & No. & $\%$ & No. & $\%$ \\
\hline Step terminating & 2 & 33 & 0 & 0 & 1 & 17 & 0 & 0 & 3 & 50 & 0 & 0 & 6 & 16 \\
\hline Unifacial spin-off >6 mm & 0 & 0 & 0 & 0 & 2 & 66.7 & 0 & 0 & 1 & 33.3 & 0 & 0 & 3 & 7.9 \\
\hline Unifacial spin-off $<6 \mathrm{~mm}$ & 0 & 0 & 0 & 0 & 4 & 50.0 & 0 & 0 & 4 & 50.0 & 0 & 0 & 8 & 21.1 \\
\hline Impact burination & 2 & 9.5 & 2 & 9.5 & 9 & 42.9 & 0 & 0 & 6 & 28.6 & 2 & 9.5 & 21 & 55.3 \\
\hline Hinge terminating & 1 & 100 & 0 & 0 & 0 & 0 & 0 & 0 & 0 & 0 & 0 & 0 & 1 & 2.6 \\
\hline Feather terminating & 1 & 14.3 & 0 & 0 & 3 & 42.9 & 0 & 0 & 2 & 28.6 & 1 & 14.3 & 7 & 18.4 \\
\hline Notch & 3 & 30 & 0 & 0 & 2 & 20 & 0 & 0 & 5 & 50 & 0 & 0 & 10 & 26.3 \\
\hline Snap fracture & 4 & 30.8 & 3 & 23.1 & 2 & 15.4 & 0 & 0 & 4 & 30.8 & 0 & 0 & 13 & 34.2 \\
\hline
\end{tabular}

\begin{tabular}{|l|r|r|r|r|r|r|r|r|r|r|r|r|r|r|}
\hline Total impact fractures & 4 & 10.5 & 2 & 5.3 & 16 & 42.1 & 0 & 0 & 14 & 37 & 2 & 5.3 & 38 & \\
\hline Total backed tools & 7 & 12.5 & 3 & 5.4 & 17 & 30.4 & 1 & 1.8 & 23 & 41.1 & 5 & 8.9 & 56 & \\
\hline Impact fractures/tool & 0.57 & & 0.67 & & 0.94 & & 0 & & 0.61 & & 0.4 & & 0.7 & \\
\hline
\end{tabular}




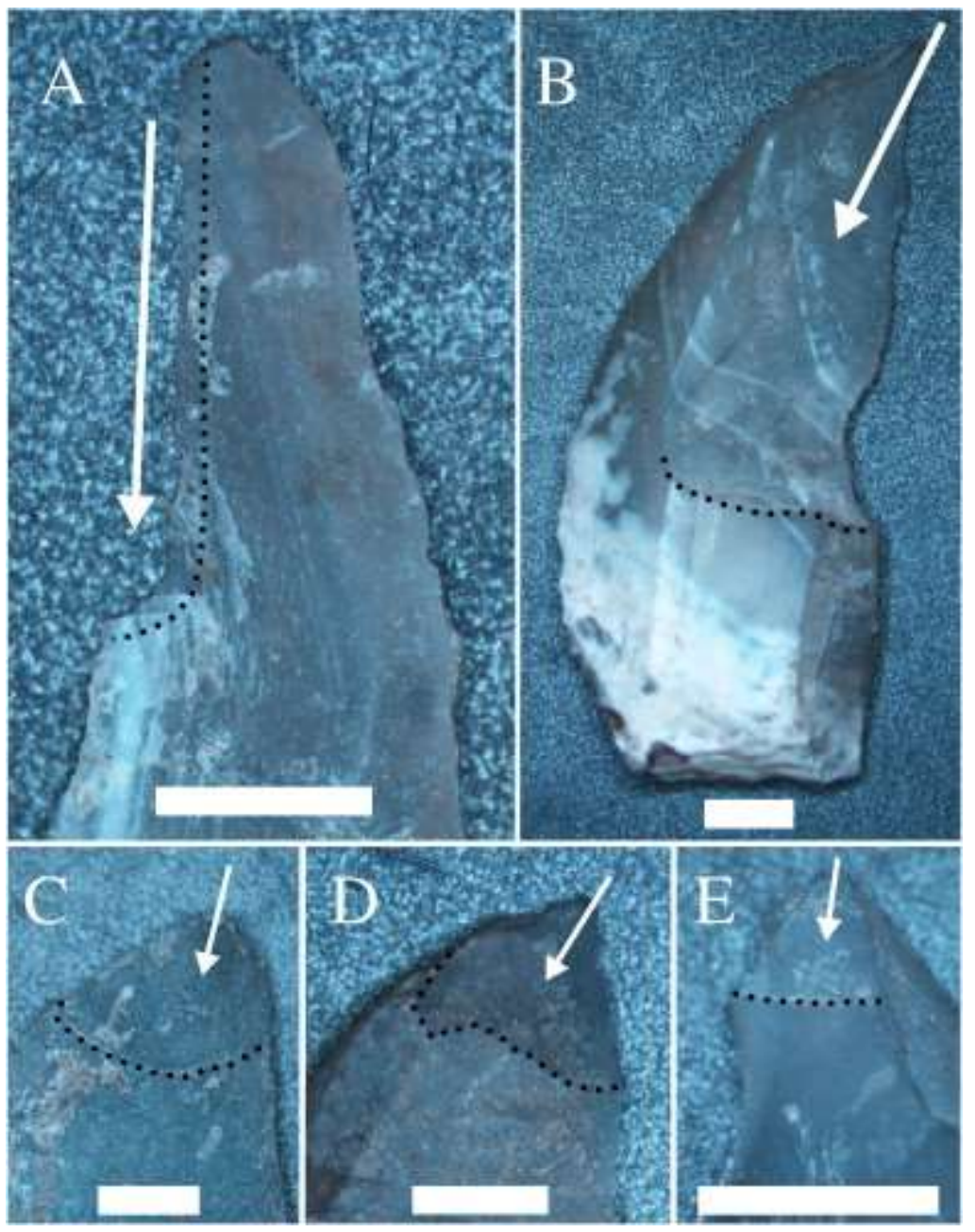

Figure 5: Some examples of backed tools from Dzombo Shelter: A \& B, segmented backed bladelet C - E, segment. Impact fractures include A, impact burination; B step terminating bending fracture (step indicated by dashed line); and C - D, unifacial spin-off fractures. Scale bar $=2 \mathbf{m m}$.

Most of the backed tools were produced on crypto-crystalline silicates (CCS; $n=39$ ), followed by agate ( $n=10$; also a CCS material but considered separately here) and lastly quartz ( $n=7$; see Table 1 for breakdown). The number of impact fractures in each raw material category is as follows (some tools possessed more than one impact fracture): $\operatorname{CCS}(n=21)$, agate $(n=12)$ and then quartz $(n=5$; Table 3). However, impact fractures per tool in each raw material category were most frequent on agate tools ( $n=1.2 /$ tool), followed by quartz $(n=0.71 /$ tool) and then CCS $(n=0.54 /$ tool). In terms of macro-fracture formation, agate also contained the most per tool $(n=1.6 /$ tool), followed by CCS $(n=$ $1.2 /$ tool) and lastly quartz $(n=0.7 /$ tool). When these results are subjected to Fisher's exact test, it is shown that there is no significant relationship between raw material and impact fracture formation. This confirms Fisher et al. (1984) and Lombard et al.'s (2004) findings in which impact fracture formation is independent of raw material. However, additional experimentation on larger samples may reveal impact formation dependence on raw material based on Pargeter's (2013) study. 
Table 3: Macro-fracture presence on raw materials: CCS, crypto-crystalline silicates.

\begin{tabular}{|l|r|r|r|r|r|r|r|r|}
\multicolumn{1}{c}{} & \multicolumn{3}{c}{ CCS } & \multicolumn{2}{c}{ Agate } & \multicolumn{2}{c|}{ Quartz } & \multicolumn{2}{c|}{ Totals } \\
\hline & \multicolumn{1}{c}{ No. } & \multicolumn{1}{c}{$\%$} & \multicolumn{1}{c}{ No. } & \multicolumn{1}{c}{$\%$} & \multicolumn{1}{c|}{ No. } & \multicolumn{1}{c|}{ \% } & No. & \multicolumn{1}{c|}{$\%$} \\
\hline Step terminating & 4 & 67 & 2 & 33 & 0 & 0 & 6 & 16 \\
\hline Unifacial spin-off $>6 \mathrm{~mm}$ & 1 & 50.0 & 1 & 50.0 & 0 & 0 & 2 & 5.3 \\
\hline Unifacial spin-off $<6 \mathrm{~mm}$ & 5 & 55.6 & 4 & 44.4 & 0 & 0 & 9 & 23.7 \\
\hline Impact burination & 11 & 52.4 & 5 & 23.8 & 5 & 23.8 & 21 & 55.3 \\
\hline Hinge terminating & 1 & 100 & 0 & 0.0 & 0 & 0 & 1 & 2.6 \\
\hline Feather terminating & 7 & 100 & 0 & 0.0 & 0 & 0 & 7 & 18.4 \\
\hline Notch & 8 & 80 & 2 & 20 & 0 & 0 & 10 & 26.3 \\
\hline Snap fracture & 11 & 84.6 & 2 & 15.4 & 0 & 0 & 13 & 34.2 \\
\hline & & & & & & & & \\
\hline Total impact fractures & 21 & 55.3 & 12 & 31.6 & 5 & 13.2 & 38 & \\
\hline Total backed tools & 39 & 69.6 & 10 & 17.9 & 7 & 12.5 & 56 & \\
\hline Impact fractures/tool & 0.54 & & 1.2 & & 0.71 & & 0.7 & \\
\hline
\end{tabular}

\subsection{Change in impact fracture frequency throughout the deposit}

To assist in understanding the shift in tool preference and impact fracture formation, the assemblage was divided into four units. The establishment of these units is based on radiocarbon dates, the diagnostic ceramic and glass bead assemblages and from a comparison with other Later Stone Age sites in the area (see Forssman 2014a, 2014b). The units are as follows: Unit A, surface to Spit IX (post-AD 1200); Unit B, Spits X to XIII (AD 1200 - 900); Unit C, Spits XIV to XVIII (AD $900-350$ ) and Unit D, Spits XIX to XXVII (AD 350 - before c. $200 \mathrm{BC}$ ). Unit D contained a low number of backed tools and impact fractures per bucket with 0.61 and 0.17 respectively ( $n=11.5$ buckets). This then sharply increased in Unit $C$ to 1.1 backed tools and 0.96 impact fractures per bucket $(n=13.6$ buckets), with similar values in Unit B containing 1.09 backed tools and 0.77 impact fractures per bucket ( $n=15.5$ buckets). Following Unit B, there is a massive drop in backed tools and impact fractures in Unit A with 0.43 and 0.28 backed tools and impact fractures per bucket $(n=39.7$ buckets), the lowest of all the units (Table 4). The odds values for Units $C$ and $D$ is 18 , showing noticeably higher odds of impact fractures forming on backed tools in Unit C. When Units $C$ and $B$ are compared an odds value of 5.3 is calculated and when Units $B$ and $A$ are compared that value is 1.27. For comparative purposes, when Unit $C$ and $A$ are compared the odds value is 6.75 . Statistically, in Unit $\mathrm{C}$ there are far higher odds of impact fractures forming than in any other unit.

We can use this information to predict change from the base of the trench into the upper levels; from Unit $D$ to $A$. It is acknowledged that there is variability between the spits but because these are arbitrary and the units represent blocks of time corresponding with Later Stone Age phases established in the extended region (van Doornum 2005), this variability becomes less pronounced. As such, from the base of the trench, backed tool and impact fracture frequencies increase massively at first and this coincides with the arrival of farmers around AD 350 (Spit XVIII; Table 5). Around AD 900 (Spit XIII) backed tools dominate the assemblage, but while their frequency and the occurrence of impact fractures declines slightly from the previous unit, it remains fairly consistent. The decrease in backed tools becomes more apparent in Unit A, yet the decline in the odds of an impact fracture 
Table 4: Macro-fracture change through spits and within Units A-C: ST, step terminating; US, unifacial spinoff; IB, impact burination; HF, hinge fracture; FF, feather fracture; N, notch; and SF, snap fracture.

\begin{tabular}{|c|c|c|c|c|c|c|c|c|c|c|c|c|c|c|}
\hline Spit & 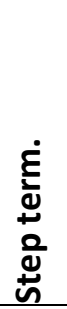 & $\begin{array}{l}\varepsilon \\
\varepsilon \\
\vdots \\
\hat{\Lambda} \\
0 \\
\omega \\
u \\
\partial\end{array}$ & 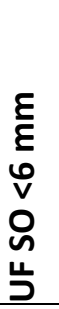 & 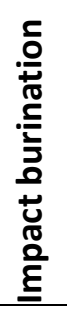 & 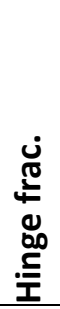 & 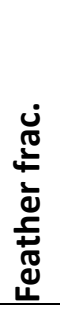 & $\begin{array}{l}\frac{1}{u} \\
\text { t } \\
\text { Z }\end{array}$ & $\begin{array}{l}\frac{0}{10} \\
\frac{5}{n}\end{array}$ & $\begin{array}{l}\frac{n}{J} \\
\stackrel{0}{0}\end{array}$ & 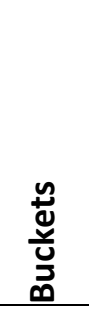 & 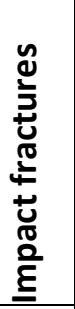 & 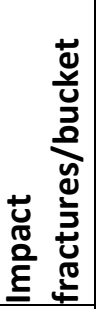 & 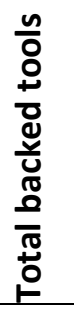 & 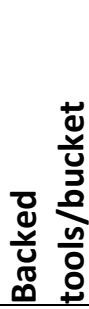 \\
\hline SUR & & & & & & & 1 & & 1 & 1.45 & 0 & 0 & 1 & 0.69 \\
\hline II & & & & & & & & 1 & 1 & 1.57 & 0 & 0 & 1 & 0.64 \\
\hline III & & & & & & & & & 0 & 4.80 & 0 & 0 & 0 & 0 \\
\hline IV & & & & & & & & & 0 & 5.15 & 0 & 0 & 0 & 0 \\
\hline V & & & & 2 & & & & & 2 & 6.14 & 2 & 0 & 1 & 0.16 \\
\hline $\mathrm{VI}$ & & & 1 & 1 & & 1 & & & 3 & 4.55 & 2 & 0.44 & 3 & 0.66 \\
\hline VII & 1 & 1 & & 2 & & & 2 & 2 & 8 & 5.72 & 4 & 0.7 & 5 & 0.87 \\
\hline VIII & 1 & 1 & & 1 & 1 & 1 & 1 & 1 & 7 & 5.62 & 3 & 0.53 & 5 & 0.89 \\
\hline IX & & & & & & & & 1 & 1 & 4.69 & 0 & 0 & 1 & 0.21 \\
\hline Totals & 2 & 2 & 1 & 6 & 1 & 2 & 4 & 5 & 23 & 39.7 & 11 & 0.28 & 17 & 0.43 \\
\hline
\end{tabular}

\begin{tabular}{|l|r|r|r|r|r|r|r|r|r|r|r|r|r|r|}
\hline $\mathrm{X}$ & & & & 1 & & & 1 & & 2 & 2.83 & 1 & 0.35 & 2 & 0.71 \\
\hline $\mathrm{XI}$ & 2 & & 3 & 1 & & & 2 & 1 & 9 & 3.97 & 6 & 1.51 & 5 & 1.26 \\
\hline \multirow{\mathrm{J}}{\mathrm{J}}{} & & & 1 & 3 & & 1 & & 2 & 7 & 3.90 & 4 & 1.03 & 8 & 2.05 \\
\hline $\mathrm{XII}$ & & & & & & & & &
\end{tabular}

\begin{tabular}{|c|c|c|c|c|c|c|c|c|c|c|c|c|c|}
\hline XIV & & & 3 & & 1 & & 1 & 5 & 2.90 & 3 & 1.03 & 3 & 1.03 \\
\hline$X V$ & 1 & 1 & 2 & & & 2 & & 6 & 3.35 & 4 & 1.2 & 5 & 1.49 \\
\hline XVI & 1 & 1 & 3 & & 1 & & & 6 & 3.06 & 5 & 1.63 & 5 & 1.63 \\
\hline XVII & & & & & & & & 0 & 2.25 & 0 & 0 & 0 & 0 \\
\hline XVIII & & 1 & & & & & & 1 & 2.05 & 1 & 0 & 2 & 0.98 \\
\hline Totals & 2 & 3 & 8 & 0 & 2 & 2 & 1 & 18 & 13.6 & 13 & 0.96 & 15 & 1.1 \\
\hline
\end{tabular}

\begin{tabular}{|l|r|r|r|r|r|r|r|r|r|r|r|r|r|r|}
\hline XIX & & & & & & 1 & & & 1 & 1.85 & 0 & 0 & 1 & 0.54 \\
\hline $\mathrm{XX}$ & & & & & & & & & 0 & 1.15 & 0 & 0 & 0 & 0 \\
\hline $\mathrm{XXI}$ & & & & & & & & & 0 & 0.85 & 0 & 0 & 0 & 0 \\
\hline $\mathrm{XXII}$ & & & & & & & & & 0 & 1.00 & 0 & 0 & 0 & 0 \\
\hline \multirow{5}{*}{} \\
\hline $\mathrm{XXIII}$ & & 1 & & & & & & 2 & 3 & 1.40 & 1 & 0.71 & 4 & 2.86 \\
\hline $\mathrm{XXIV}$ & & & & & & & & & 0 & 1.65 & 0 & 0 & 0 & 0 \\
\hline $\mathrm{XXV}$ & & & & & & & & & 0 & 1.05 & 0 & 0 & 1 & 0.95 \\
\hline $\mathrm{XXVI}$ & & & & 1 & & & & 1 & 2 & 1.15 & 1 & 0.87 & 1 & 0.87 \\
\hline $\mathrm{XXVII}$ & & & & & & & & & 0 & 1.40 & 0 & 0 & 0 & 0 \\
\hline Totals & 0 & 1 & 0 & 1 & 0 & 1 & 0 & 3 & 6 & 11.5 & 2 & 0.17 & 7 & 0.61 \\
\hline
\end{tabular}

\begin{tabular}{lllllllllllllll} 
All totals & 6 & 3 & 8 & 21 & 1 & 7 & 10 & 13 & 69 & 80.3 & 38 & 0.86 & 56 & 0.7 \\
\hline
\end{tabular}


Table 5: Comparing impact fractures from each unit shows a peak in Unit B and C further emphasised when notches (inc. notches) are included.

\begin{tabular}{|c|c|c|c|c|c|c|c|}
\hline & $\begin{array}{l}\text { Total } \\
\text { MFs }\end{array}$ & IFs & $\begin{array}{l}\% \text { of } \\
\text { total }\end{array}$ & /buc. & $\begin{array}{l}\text { Inc. } \\
\text { notches }\end{array}$ & $\begin{array}{l}\% \text { of } \\
\text { total }\end{array}$ & /buc. \\
\hline Unit A & 23 & 11 & 47.83 & 0.28 & 15 & 65.22 & 0.38 \\
\hline Unit B & 22 & 12 & 54.55 & 0.77 & 16 & 72.73 & 1.03 \\
\hline Unit C & 18 & 13 & 72.22 & 0.96 & 15 & 83.33 & 1.10 \\
\hline Unit D & 6 & 2 & 33.33 & 0.17 & 2 & 33.33 & 0.17 \\
\hline
\end{tabular}

forming is not as distinct and they still occur regularly. To assess what the driving factors behind this shift might be, farmer- and trade-associated artefacts and the faunal assemblage are now considered.

\subsection{Ceramics, beads, metal and bone tools}

Certain items found at Dzombo were likely to have been acquired from farmers and this includes ceramics, beads and metal items. Shell and bone beads and bone tools are also possibly linked to trade with farmers as argued by Hall and Smith (2000) for Little Muck Shelter. Therefore, by comparing changes in these categories between the units it is possible to track shifts in artefact acquisition and production (Table 6). All categories are found in Unit A where ceramics (1.36/bucket), glass beads (0.43/bucket) and bone tools $(0.2 /$ bucket $)$ were found their highest density along with all of the metal items $(0.25 /$ bucket $)$. However, shell beads $(1.16 /$ bucket $)$, which include ostrich eggshell and land snail shell, and bone beads $(0.58 /$ bucket $)$ were more frequent in Unit B while no category was found at its greatest density in Units C or D. It seems, based on this, that there is a general increase in the density of most artefacts presented here from Unit $D$ (1.04/bucket) through Unit C (1.47/bucket) into Unit B (1.94/bucket), and then another increase into Unit A (2.87/bucket) with ceramic, glass bead and bone tool densities increasing and metal appearing for the first time.

\subsection{Faunal assemblage}

Changing patterns in hunting tool technology might also have impacted the faunal record, and between the units identified above certain differences are noticed (see Forssman 2014a, 2014b for additional details). First, the mass of fauna recovered in each unit varied. Faunal density increases from Unit $D(29.4 \mathrm{~g} /$ bucket $)$ into Unit $C(47.66 \mathrm{~g} /$ bucket $)$ where it is at its peak. Following a slight decline from Unit C into Unit B (44.43 g/bucket), fauna drops to its lowest density in Unit A (24.89 $\mathrm{g} /$ bucket). These figures may relate to the population using the rockshelter but it might be that during Units B and C foragers were hunting more often or their hunts were more successful. Second, 37 animal categories were identified, which includes species and, where applicable, size classes within each family or species (for example small, medium and large bovids). Most came from Unit A ( $n=29$ types; $n=326$ specimens), possibly indicating an expansion of the foraging subsistence base during times when farmers were more active in the area, followed by Units $B$ ( $n=17$ types; $n=172$ specimens), $C(n=15$ types; $n=181$ specimens) and $\mathrm{D}(n=9$ types; $n=65)$. However, per bucket Unit $C$ contained both the greatest variety of identifiable specimens $(n=1.1)$ and density of the total number of identifiable specimens (NISP; $n=13.31)$, followed closely by Unit $\mathrm{B}(n=1.09 ;$ NISP $n=$ 
Table 6: Ceramic, bead, metal and bone tool numbers and density between the different units. Total no. is the total of each category across the units, total is the total of all categories within a unit and / buc. refers to the number of NISP per 13 I bucket.

\begin{tabular}{|c|c|c|c|c|c|c|c|c|c|c|c|c|c|}
\hline & \multicolumn{2}{|l|}{ Total } & \multicolumn{2}{|c|}{ Unit A } & \multicolumn{3}{|c|}{ Unit B } & \multicolumn{3}{|c|}{ Unit C } & \multicolumn{3}{|c|}{ Unit D } \\
\hline & No. & No. & $\%$ & /buc. & No. & $\%$ & /buc. & No. & $\%$ & /buc. & No. & $\%$ & /buc. \\
\hline Ceramics & 61 & 54 & 88.52 & 1.36 & 3 & 4.92 & 0.19 & 3 & 4.92 & 0.22 & 1 & 1.64 & 0.09 \\
\hline Shell beads & 48 & 13 & 27.08 & 0.33 & 18 & 37.5 & 1.16 & 10 & 20.83 & 0.74 & 7 & 14.58 & 0.61 \\
\hline Bone beads & 30 & 12 & 40 & 0.30 & 9 & 30 & 0.58 & 5 & 17 & 0.37 & 4 & 13 & 0.35 \\
\hline Glass beads & 18 & 17 & 94.44 & 0.43 & 0 & 0 & 0 & 1 & 5.56 & 0.07 & 0 & 0 & 0 \\
\hline Metal & 10 & 10 & 100 & 0.25 & 0 & 0 & 0 & 0 & 0 & 0 & 0 & 0 & 0 \\
\hline Bone tools & 9 & 8 & 88.89 & 0.20 & 0 & 0 & 0 & 1 & 11.11 & 0.07 & 0 & 0 & 0 \\
\hline Total & 176 & 114 & 64.77 & 2.87 & 30 & 17.05 & 1.94 & 20 & 11.36 & 1.47 & 12 & 6.82 & 1.04 \\
\hline
\end{tabular}

Table 7: Faunal comparison between Units A, B and C. Total mass includes non-identified faunal remains and /buc. refers to the number of NISP per 13 I bucket.

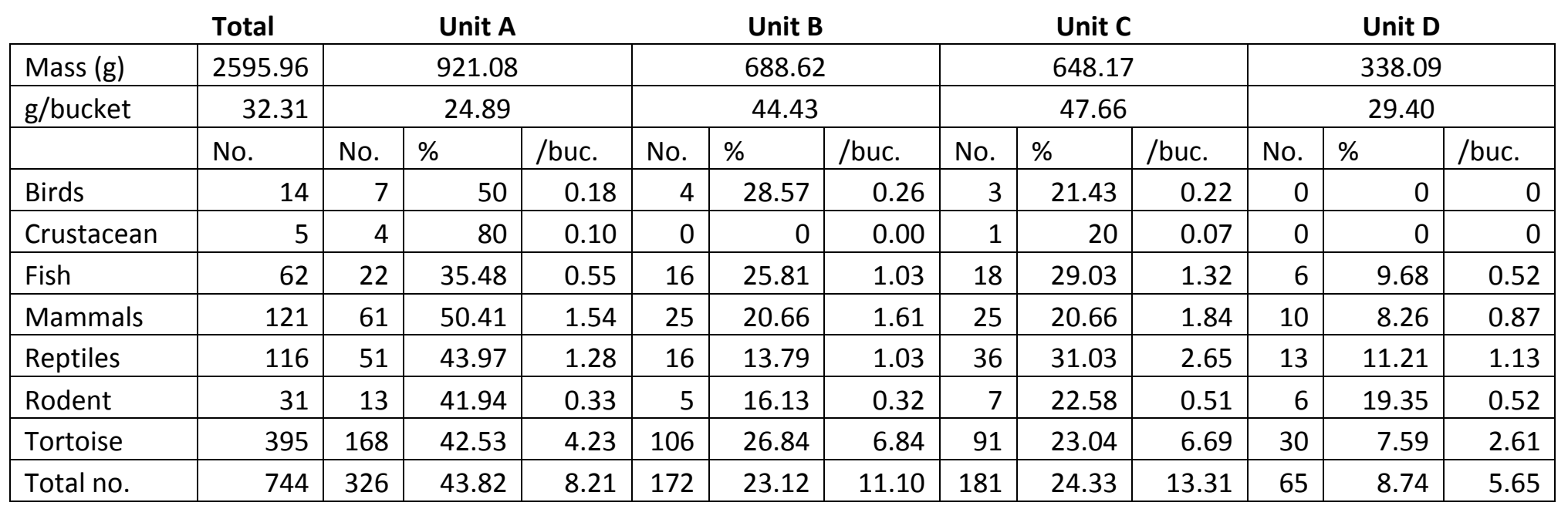


11.1) and then Units A and D ( $n=0.78$ each but NISP $n=8.21$ and 5.65 respectively). Additionally, two possible ovicapra patella found in Unit B (Spit XII) were possibly acquired from Khoekhoe herders or farmers; no evidence yet suggests foragers were herding livestock but it remains a possibility. These findings show a shift in animal utilisation between the units. They suggest that during Units $B$ and $C$ a slightly greater variety of species was being utilised, even though Unit $A$ contains the most diverse assemblage. Additionally, in Unit $\mathrm{C}$ the greatest degree of animal exploitation occurred (Table 7). In summary, little compelling evidence exists to indicate that hunting activities, or species utilisation, changed significantly.

\section{Discussion}

The macro-fracture study at Dzombo provides evidence for shifting stone tool impact-related activities over the course of the last 2000 years. It is suggested that these could be due to increased hunting activities linked to changing opportunities or social dynamics. By performing such an analysis, which can be relatively easily achieved, further details about Stone Age lifeways are revealed, assisting with the understanding of site specific, as in this case, but also regional behaviour patterns. The results here strongly show the value of performing a macro-fracture analysis on stone tools, and presumably other artefacts including bone tools (e.g. Bradfield 2012), because of its ability to help recognise the changing importance of hunting over the course of a site's occupation and its implications in either shifting site function or forager-farmer interactions.

The most frequent tool form to fracture, and which also had the highest number of broken versus complete forms, was backed bladelets. There are various possible explanations but without additional tests it cannot be determined which is most likely. It may be that the elongated but fairly symmetrical shape of a bladelet is more prone to snapping on impact (e.g. Knecht 1993, 1997; Ellis 1997), known to assist in causing a more severe wound (Lombard \& Parsons 2008), but might have been broken intentionally to create tool insets (Bergman et al. 1987). However, it could also be that this tool form was used more intensively due to it being favoured (Bousman 2005) or because of specific resource procurement strategies (Lombard \& Parsons 2008); the low number of impact fractures does not help determine which tasks these tools were used for. Segmented backed bladelets were most likely to develop impact fractures, yet it cannot be said whether this is because the tool's morphology has a greater propensity to break or if they were used more frequently. Segments contained fewer fractures in general even though they are the most frequent tool form. For this reason, it is difficult to imagine that they were not favoured over other tools - if so why produce them most often - but it could be that they were not intensely used, used in tasks less likely to damage the tools, or are morphologically more robust.

The most likely raw material to fracture was agate even though quartz contained the greatest amount of impact fractures per tool. The fractures on agate tools are mostly associated with impact suggesting that this raw material may be a good indicator of related activities; CCS, for example, contained a mixture of fracture types, not all of which are associated with impact. Similarly, quartz contained fractures mostly relating to impact damage (four from five). If quartz fractures readily, it would be expected that, in addition to these, other fracture types would also have been identified including from post-depositional process. Perhaps, as is the argument with analysing flint (Tallavaara et al. 2010) or chert (Driscoll 2011) stone tool assemblages, quartz needs to be treated differently because of its fragmentation qualities. The statistical analysis on the occurrence of impact fractures 
on both tool types and raw material revealed an independent relationship and so the suggestions made here must be tested under more stringent conditions and with a large sample.

Tool form and raw material aside, the occurrence of step terminating fractures (9\%), unifacial spinoff fractures (15.9\%) and impact burinations (30.4\%), making up $55.1 \%$ of all fractures, indicates that a large proportion of backed tools were most likely used as impact weapon tips. The reasons this increased from approximately AD 350 (Unit C) might relate to either forager-farmer interactions or a change in site function. To assess which may have played a role, the remaining assemblage is relied upon and specifically the artefacts that would have been acquired from farming people or that could indicate a change in the site's function.

If site function changed there is very little material evidence indicating this. For example, had the site become an aggregation camp, as discussed by Wadley (1986) with reference to Jubilee Shelter in the Magaliesberg, South Africa, one could expect to find possible ritual-orientated items, such as ochre, crystals and even Early or Middle Stone Age artefacts; goods used for hxaro or reciprocal gift exchange, which includes jewellery (see Mitchell 2003); and evidence of feasting most likely seen in an increase in faunal remains (e.g. Sadr 2004; Plug et al. 2010). The production of rock art might also have occurred during this phase (e.g. Carter 1970; Manhire et al. 1984; Barham \& Mitchell 2008). The only major artefact shifts that occurred at Dzombo, other than the shift in scraper/backed tool preference in Unit B, is the increase in farmer-associated items and bone tools in Unit A, at which point scrapers once again dominate the assemblage. The lack of change from Unit D until Unit $B$ does not strongly indicate a shift in site function, but possibly an increase in the number of foragers using the site or the intensity of the site's occupation. It is also during this time, from Unit C, that trade began based on the appearance of farmer-related items and an increase in shell bead production. Had population or activities increased at the site, it is not likely that backed tools alone would increase and dominate the assemblage. Predictably, an increase in either case would correspondingly increase all activities, and thus all artefact types. Perhaps site function does not sufficiently explain the changing relationship of scrapers and backed tools, as well as the latter's use.

Since it appears that Dzombo's function as a residential site remained largely similar between Units $B, C$ and $D$, the increase in backed tools and their later dominance might then relate to foragerfarmer relations. Dzombo's sequence follows much the same progressions as other Later Stone Age sites around southern Africa: from what has been interpreted as the beginning of contact with farmers - around Spit XVIII based on radiocarbon dates and the appearance of ceramics - scrapers dominate the formal assemblage. This changes when backed tools dominate from the Zhizo period occupation of the site, beginning c. AD 900, continuing until approximately AD 1200. Thus, the increased production of backed tools and the occurrence of impact fractures correspond with the arrival of farming people. This, as other scholars have suggested, might be linked to increased hunting activities to acquire animal-derived products for trade purposes. If so, it could also explain the relative continuity in the faunal record; animals were hunted for trade purposes and not brought back to the site. One might then ask what foragers received in return for animal products since only a few farmer-associated items were recovered. However, this is based on two premises. The first is that foragers were trading for items that would preserve in the archaeological record when in fact they might have been perishable, and the second is that these acquisitions would be brought to the rockshelter as opposed to deposited/consumed at another site occupied during times of trade. Of further interest is the lack of metal in Units B and C, which, based on current thinking, replaced the 
need for stone hunting implements (e.g. Hall \& Smith 2000). Previous arguments addressing similar stone tool shifts have tended to rely on a lack of evidence; backed tools decline because metal was adopted even though no or very little metal has been found in the archaeological record. It is in fact only in Unit A when metal appears that backed tool numbers decline and scraper frequencies once again dominate, possibly indicating that at this point in time metal replaced stone in hunting tools. This is made less likely since impact fracture frequencies and the odds of them forming on backed tools remained high suggesting impact-related activities using stone tools continued. Therefore, despite these changes in backed tool frequencies, Dzombo contains strong indicators suggesting that hunting activities increased from the onset of contact with farmers, a finding not definitively shown at many Later Stone Age sites, even though suggested.

\section{Conclusions}

A sudden increase in the density and dominance of backed tools from Spit X until XIII at Dzombo prompted further inquiry into the use and shifting preference of backed tools over the site's 2000 year occupation. To explain this, backed tools were subjected to a macro-fracture analysis with the aim of identifying impact fractures in order to assess whether hunting activities increased during this time. The analysis revealed that segmented backed bladelets possessed the most impact fractures while backed bladelets as a whole contained the most fractures, including those not related to impact. Agate, a CCS material, is the most likely raw material to fracture but other CCS materials were favoured based on their dominance at the site. It was also found that differences existed between what are labelled here as Unit A (surface - Spit IX), Unit B (Spits X - XIII), Unit C (Spits XIV XVIII) and Unit D (Spits XIX - XXVII). Namely, backed tool and macro-fracture densities are at their highest in Units $B$ and $C$, suggesting that backed tools produced during these phases were used more intensively or that post-depositional macro-fracturing occurred. But, the presence of impact burinations, unifacial spin-off and step terminating fractures indicates that impact-related activities are largely responsible for the formation of fractures on Dzombo's backed assemblage. Two possibilities might explain this increase; forager-farmer interactions and site function. Little evidence was found to support the latter possibility and so it seems that increases in impact-related practices, interpreted here as linked to hunting activities, were associated with forager-farmer interactions. Changes in the faunal assemblage should not necessarily be expected since animal products were traded away from and not deposited at the site. Farmer-associated items also cannot be relied on to indicate trade because remuneration received by foragers might have been perishable or not returned to the rockshelter. Performing a macro-fracture study has nevertheless revealed evidence supporting claims that hunting increased when foragers and farmers came into contact with one another and has helped contribute to the growing body of work exposing inter-cultural relationships occurring on different landscapes across southern Africa.

\section{Acknowledgements}

I would like to extend my deep gratitude to the Palaeontological Scientific Trust and their Scatterlings of Africa program for funding as well as the National Research Fund for assistance. I am also grateful for the guidance given by Justin Pargeter and Alexander Antonites and for commenting on an earlier draft Justin Bradfield, Matt Caruana, Justin Pargeter and two anonymous reviewers. Lara Kraljevic, Devin Murray, Ruan van der Merwe and Chené Wilbers assisted with laboratory work. 


\section{References}

Antonites, A.R. 2014. An archaeological investigation of Zhizo/Leokwe foodways at Schroda and Pont Drift, Limpopo Valley, South Africa. Unpublished PhD dissertation. Yale: Yale University.

Barham, L. \& Mitchell, P. 2008. The First Africans: African archaeology from the earliest toolmakers to the most recent foragers. Cambridge: Cambridge University Press.

Bergman, C.A., Barton, R.N.E., Collcutt, S.N. \& Morris, G. 1987. Intentional breakage in a late upper Palaeolithic assemblage from southern England. In: Sieveking, G. de G. \& Newcomer, M.H. (eds) The Human Uses of Flint and Chert: 21-32. Cambridge: Cambridge University Press.

Binneman, J. 1983. Microscopic examination of a hafted tool. South African Archaeological Bulletin 38: 93-95.

Binneman, J. 1997. Usewear traces on Robberg bladelets from Rose Cottage Cave. South African Journal of Science 93: 479-481.

Binneman, J. \& Mitchell, P.J. 1997. Usewear analysis of Robberg bladelets from Sehonghong Shelter, Lesotho. Southern African Field Archaeology 6: 42-49.

Bird, R.B. 2007. Fishing and the sexual division of labor among the Meriam. American Anthropologist 109: 442-451.

Boëda, E. Geneste, J.M. \& Griggo, C. 1999. A Levallois point embedded in the vertebra of (Equus africanus): hafting, projectiles and Mousterian hunting weapons. Antiquity 73: 394-402.

Bousman, C.B. 2005. Coping with risk: Later Stone Age technological strategies at Blydefontein Rock Shelter, South Africa. Journal of Anthropological Archaeology 24: 193-226.

Bradfield, J. 2012. Macrofractures on bone-tipped arrows: analysis of hunter-gatherer arrows in the Fourie collection from Namibia. Antiquity 86: 1179-1191.

Bradfield, J. \& Lombard, M. 2011. A macrofracture study of bone points used in experimental hunting with reference to the South African Middle Stone Age. South African Archaeological Bulletin 66: 67-76.

Calabrese, J.A. 2000. Metals, ideology and power: the manufacture and control of materialised ideology in the area of the Limpopo-Shashe confluence, c. AD 900 to 1300. Goodwin Series 8: 100111.

Carter, P.L. 1970. Late Stone Age exploitation patterns in southern Natal. South African Archaeological Bulletin 25: 55-58.

Deacon, H.J. 1989. Late Pleistocene palaeoecology and archaeology in the southern Cape, South Africa. In: Mellars, P. \& Stringer, C. (eds) The Human Revolution: behavioural and biological perspectives in the origins of modern humans: 547-564. Edinburgh: Edinburgh University Press.

Deacon, H.J. 1995. Two Late Pleistocene-Holocene archaeological depositories from the southern Cape, South Africa. South African Archaeological Bulletin 50: 121-131. 
Deacon, H.J. \& Deacon J. 1980. The hafting, function and distribution of small convex scrapers with an example from Boomplaas Cave. South African Archaeological Bulletin 35: 31-37.

Deacon, J. 1984a. Later Stone Age people and their descendants in southern Africa. In: Klein, R. (ed.) Southern African Prehistory and Paleoenvironment: 221-328. Rotterdam: Balkema.

Deacon, J. 1984b. The Later Stone Age of Southernmost Africa. Cambridge: Cambridge Monographs in African Archaeology 12: BAR International.

Dockall, J.E. 1997. Wear traces and projectile impact: A review of the experimental and archaeological evidence. Journal of Field Archaeology 24: 321-331.

Driscoll, K. 2011. Vein quartz in lithic traditions: an analysis based on experimental archaeology. Journal of Archaeological Science 38: 734-745.

Ellis, C.J. 1997. Factors influencing the use of stone projectile tips: an ethnographic perspective In: Knecht, H. (ed.) Projectile Technology: interdisciplinary contributions to archaeology: 37-74. New York: Plenum Press.

Fischer, A., Hansen, P.V. \& Rasmussen, P. 1984. Macro and micro wear traces on lithic projectile points: experimental results and prehistoric examples. Journal of Danish Archaeology 3: 19-46.

Fisher, R.A. 1973. Statistical Methods and Scientific Inference. New York: Hafner.

Forssman, T. 2014a. The spaces between places: a landscape study of foragers on the greater Mapungubwe landscape. Unpublished PhD dissertation. Oxford: University of Oxford.

Forssman, T. 2014b. Dzombo Shelter: a contribution to the Later Stone Age sequence on the Greater Mapungubwe Landscape. Southern African Archaeological Bulletin 69: 182-191.

Graves, D. 2011. The use of predictive modelling to target Neolithic settlement and occupation activity in mainland Scotland. Journal of Archaeological Science 38: 633-656.

Hall, S.L. \& Smith, B.W. 2000. Empowering places: rock shelters and ritual control in farmer-forager interactions in the Northern Province. Goodwin Series 8: 30-46.

Huffman, T.N. 2000. Mapungubwe and the origins of the Zimbabwe culture. South African Archaeological Society Goodwin Series 8, 14-29.

Huffman, T.N. 2007. Handbook to the Iron Age: the archaeology of pre-colonial farming societies in southern Africa. Cape Town: University of KwaZulu-Natal Press. Knecht, H. 1993. Early Upper Paleolithic approaches to bone and antler projectile technology. In: Peterkin, G.L., Bricker, H.M. \& Mellars, P. (eds) Hunting and Animal Exploitation in the Later Paleolithic and Mesolithic of Eurasia: 33-47. Arlington: Archaeological Papers of the American Anthropological Association 4.

Knecht, H. 1997. Projectile points of bone, antler and stone: experimental explorations of manufacture and use. In: Knecht, H. (ed.) Projectile Technology: interdisciplinary contributions to archaeology: 191-121. New York: Plenum Press. 
Lombard, M. 2004. Distribution patterns of organic residues on Middle Stone Age Points from Sibudu Cave, Kwazulu-Natal, South Africa. South African Archaeological Bulletin 59: 37-44.

Lombard, M. 2005. A method for identifying Stone Age hunting tools. South African Archaeological Bulletin 60: 115-120.

Lombard, M. 2007. Evidence for change in Middle Stone Age hunting behaviour at Blombos Cave: results of a macrofracture analysis. South African Archaeological Bulletin 62: 62-67.

Lombard, M. 2011. Quartz-tipped arrows older than 60 ka: further use-trace evidence from Sibudu, KwaZulu-Natal, South Africa. Journal of Archaeological Science 38: 1918-1930.

Lombard, M. \& Pargeter, J. 2008. Hunting with Howiesons Poort segments: Pilot experimental study and the functional interpretation of archaeological tools. Journal of Archaeological Science 35: 25232531.

Lombard, M. \& Parsons, I. 2008. Blade and bladelet function and variability in risk Management during the last 2000 years in the Northern Cape. South African Archaeological Bulletin 63: 18-27.

Lombard, M., Parsons, I. \& van der Ryst, M.M. 2004. Middle Stone Age lithic point experimentation for macro-fracture and residue analyses: the process and preliminary results with reference to Sibudu Cave points. South African Journal of Science 100: 159-166.

Lombard, M., Wadley, L., Deacon, J., Wurz, S., Parsons, I., Mohapi, M., Swart, J. \& Mitchell, P.J. 2012. South African and Lesotho Stone Age sequence update (I). South African Archaeological Bulletin 67: 123-144.

Manhire, T., Parkington, J.E. \& van Rijssen, B. 1984. A distributional approach to the interpretation of rock art in the south-western Cape. Goodwin Series 4: 29-33.

Mitchell, P.J. 2003. Anyone for hxaro? Thoughts on the theory and practice of exchange in southern African Later Stone Age archaeology. In: Mitchell, P.J., Haour, A. \& Hobart, J. (eds) Researching Africa's Past: new contributions from British archaeologists: 35-43. Oxford: Oxford University School of Archaeology.

Mohapi, M. 2008. A new angle on Middle Stone Age hunting technology in South Africa. Unpublished PhD dissertation. Johannesburg: University of the Witwatersrand.

Odell, G.H. \& Cowan, F. 1986. Experiments with spears and arrows on animal targets. Journal of Field Archaeology 13: 194-212.

Parkington, J.E. 1980. Time and place: some observations on spatial and temporal patterning in the Later Stone Age sequence in southern Africa. South African Archaeological Bulletin 55: 73-112.

Pargeter, J. 2011. At the Tip of the Matter: understanding later Stone Age hunting technologies in a southern African context. Saarbrücken: Lambert Academic Publishing.

Pargeter, J. 2013. Rock type variability and impact fracture formation: working towards .a more robust macrofracture method. Journal of Archaeological Science 40: 4056-4065. 
Pargeter, J. \& Bradfield J. 2012. The effects of Class I and II sized bovids on macrofracture formation and tool displacement: results of a strampling experiment in a southern African Stone Age context. Journal of Field Archaeology 37: 238-257.

Plug, I. 1988. Hunters and herders: an archaeozoological study of some prehistoric communities in the Kruger National Park. Unpublished PhD dissertation. Pretoria: University of Pretoria.

Plug, I., Mitchell, P.J. \& Bailey, G. 2010. Late Holocene fishing strategies in southern Africa as seen from Likoaeng, highland Lesotho. Journal of Archaeological Science 37: 3111-3123.

Sadr, K. 1997. Kalahari archaeology and the Bushmen debate. Current Anthropology 38: 104-112.

Sadr, K. 2002. Encapsulated Bushmen in the archaeology of Thamaga. In: Kent, S. (ed.) Ethnicity, Hunter-gatherers, and the "Other": association or assimilation in Africa: 28-47. Washington: Smithsonian Institution Press.

Sadr, K. 2004. Foragers and herders on Kasteelberg during the first millennium AD. The Digging Stick 21: 1-4.

Schweitzer, F.R. \& Wilson, M.L. 1982. Byneskranskop 1: a late Quaternary living site in the southern Cape Province, South Africa. Annals of the South African Museum 88: 1-203.

Shea, J.J. 2009. The impact of projectile weaponry on Late Pleistocene hominin evolution. In: Richards, M. \& Hublin, J.J. (eds) The Evolution of Hominid Diets: integrating approaches to the study of paleolithic subsistence: 189-199. Dordrecht: Springer.

Tallavaara, M., Manninen, M.A., Hertell, E. \& Rankama, T. 2010. How flakes scatter: a critical evaluation of quartz fracture analysis. Journal of Archaeological Science 37: 2442-2448.

Upton, G.J.G. 1992. Fisher's exact test. Journal of the Royal Statistical Society 155: 395-402.

Wadley, L. 1986. A social and ecological interpretation of the Later Stone Age in the southern Transvaal. Unpublished PhD dissertation. Johannesburg: University of the Witwatersrand.

Wadley, L. 1987. Later Stone Age Hunters and Gatherers of the Southern Transvaal. Oxford: BAR International Series 380.

Wadley, L. 1996. Changes in the social relations of precolonial hunter-gatherers after agropastoralist contact: an example from the Magaliesberg, South Africa. Journal of Anthropological Archaeology 15: 205-217.

Walker, N.J. 1994. The Late Stone Age of Botswana: some recent excavations. Botswana Notes and Records 26: 1-35.

Van Doornum, B.L. 2005. Changing Places, Spaces and Identity in the Shashe-Limpopo Region of Limpopo Province, South Africa. Unpublished PhD dissertation. Johannesburg: University of the Witwatersrand.

Villa, P. \& Soriano, S. 2010. Hunting weapons of Neanderthals and early Modern Humans in South Africa: Similarities and differences. Journal of Anthropological Research 66: 5-38. 
Villa, P. Soriano, S., Teyssandier, N. \& Wurz, S. 2010. The Howiesons Poort and MSA III at Klasies River main site, Cave 1A. Journal of Archaeological Science 37: 630-655.

Voigt, E.A. 1980. Reconstructing Iron Age economies of the northern Transvaal. South African Archaeological Bulletin 35: 39-45.

Voigt, E.A. 1981. The faunal remains from Schroda. In: Voigt, E.A. (ed.) A Guide to Archaeological Sites in the Northern and Eastern Transvaal: 55-60. Pretoria: Transvaal Museum.

Voigt, E.A. \& Plug, I. 1981. Early Iron Age Herders of the Limpopo Valley. Pretoria: Transvaal Museum.

Yaroshevich, A., Kaufman, D., Nuzhnyy, D., Bar-Yosef, O. \& Weinstein-Evron, M. 2010. Design and performance of microlith implemented projectiles during the Middle and the Late Epipaleolithic of the Levant: experimental and archaeological evidence. Journal of Archaeological Science 37: 368388. 